\title{
FACTORS RELATED TO THE INCIDENCE OF SECONDARY HAEMORRHAGE IN 462 PATIENTS WITH TRAUMATIC HYPHAEMA
}

\author{
C. S. NG, N. P. STRONG, J. M. SPARROW, A. R. ROSENTHAL \\ Leicester
}

\begin{abstract}
SUMMARY
In a retrospective study of $\mathbf{4 6 2}$ in-patients with traumatic hyphaema, secondary haemorrhage occurred in $8.7 \%$ of patients. A multivariate analysis demonstrated that the size of hyphaema on presentation and the presence of retinal damage did not affect the probability of secondary haemorrhage. The incidence of secondary haemorrhage was found to decrease by approximately half with the use of topical steroid ( $p=0.005$ ), but did not appear to be influenced by the use of cycloplegics. These data indicate in an unselected sequential population of patients, the therapeutic importance of topical steroid in the treatment of blunt ocular trauma.
\end{abstract}

The incidence of secondary haemorrhage after traumatic hyphaema has been reported to be between $2.4 \%$ and $38 \% .^{1-21}$ Higher estimates in general derive from studies performed in the United States, ${ }^{12-21}$ and lower estimates from those performed elsewhere. ${ }^{1-11}$ In addition to this apparent regional variation, there is a further considerable variation in the reported incidence of secondary haemorrhage from studies performed within the United States and also from those performed in Northern European countries.

Various studies have suggested treatment regimes directed towards the prevention of secondary haemorrhage, including the use of topical ${ }^{1,9}$ or systemic ${ }^{22-24}$ steroids, cycloplegics ${ }^{1,9,25}$ and antifibrinolytics. ${ }^{26-31}$

This study assessed the incidence of secondary haemorrhage following traumatic hyphaema. Factors pertinent to the injury and to the type of treatment employed have been examined to determine the best method of treatment in the prevention of secondary haemorrhage.

\section{PATIENTS AND METHODS}

The hospital notes of 462 patients with traumatic

Correspondence to: Dr C S Ng, Department of Ophthalmology, Leicester Royal Infirmary, Leicester LE1 5WW. hyphaema who were admitted to the ophthalmic wards at the Leicester Royal Infirmary between January 1979 and February 1990 were reviewed retrospectively. Patients with a post-operative hyphaema, penetrating injuries and a non-traumatic hyphaema (eg secondary to rubeosis iridis or other pathology) were excluded. Patients who were managed as out-patients were also excluded. The Leicester Royal Infirmary is the only ophthalmological facility serving the Leicestershire area and has a drainage population of approximately one million. This department does not function as a centre for tertiary referral.

The data collected on each patient included age, sex, nature of the injury, grade of initial hyphaema, intra-ocular pressure on presentation, treatment, the presence of complications (including secondary haemorrhage and retinal injuries), and miscellaneous information deemed relevant to individual cases.

From the information in the hospital notes, the initial hyphaema was graded into five groups: microscopic, if layering of blood was not seen in the anterior chamber on slit-lamp examination; grade 1 if less than a third of the anterior chamber was filled with blood clot; grade 2 if more than a third but less than half of the anterior chamber was filled; grade 3 if more than half of the anterior chamber was filled; and grade 4 if there was a total hyphaema. ${ }^{4}$ Secondary haemorrhage was defined as having occurred when there was fresh layering of blood in the anterior chamber on slit lamp examination.

Although management varied on different surgical firms during the study, it has been standard practice throughout to admit patients with traumatic hyphaema to the wards for bed rest, and to treat any associated corneal abrasion with topical antibiotics and an eye pad. Patching of the eye was not used for the primary treatment of the hyphaema. Treatment with cycloplegics, topical steroids and antifibrinolytics was, however, not standardised. 
FIG 1: AGE DISTRIBUTION OF PATIENTS

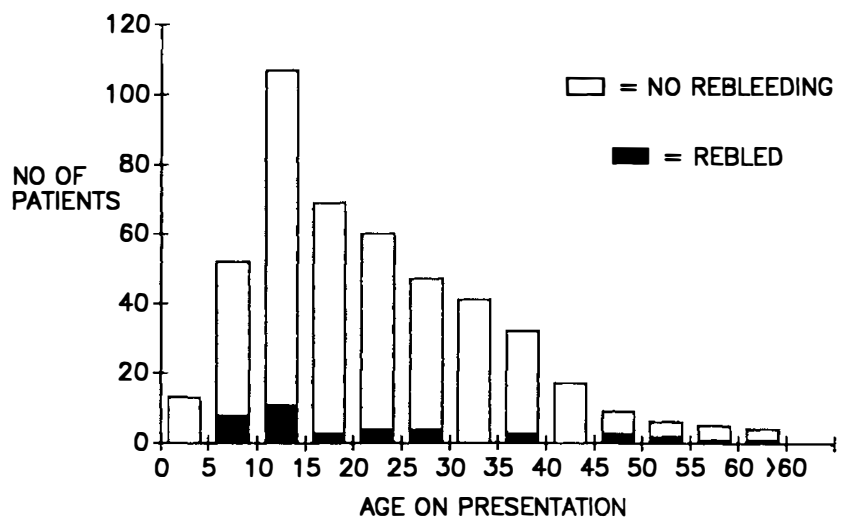

Fig. 1. Age distribution of patients showing those who suffered secondary haemorrhage following traumatic hyphaema (filled bar sections).

These were used either alone, or in various combinations. Patients with raised intra-ocular pressure were treated with topical anti-hypertensives and/or systemic acetazolamide. Surgical evacuation of the clot was rarely performed. Retinal injuries were recorded at various points in patients' follow-up, depending on the visibility of the posterior ocular segment.

\section{STATISTICAL METHODS}

A sequential multivariate analysis was performed to determine risk factors related to the injury, and effects of treatment on outcome. The main outcome variable was the occurrence of a secondary haemorrhage. This was modelled using a multiple logistic regression and factor analysis. In all analyses, prior adjustment for age and sex was made, and when examining effects of treatment the variables related to the injury itself were treated as confounding variables. The analysis was performed using the Generalised Linear Interactive Modelling (GLIM)* system.

\section{RESULTS}

The patients were aged between one and 72 years $($ mean $=22.56$, standard deviation $=12.49$, median $=20$ years) (see Fig. 1 for age distribution). Of the 462 patients, $369(79 \%$ ) were male (male:female ratio $=4: 1$ ).

Table I. Causes of traumatic hyphaema

\begin{tabular}{lcc}
\hline Cause & Number & (Rebleed) \\
\hline Sporting injuries & 205 & $(14)$ \\
Childhood injuries & 60 & $(10)$ \\
Fight/alleged assault & 39 & $(3)$ \\
Occupational injuries & 21 & $(2)$ \\
Domestic injuries (DIY) & 17 & $(2)$ \\
Other domestic injuries & 8 & \\
Road traffic accidents & 2 & $(9)$ \\
Other accidents & 110 & $(40)$ \\
Total & 462 & \\
\hline
\end{tabular}

*GLIM, Numerical Algorithms Group Ltd (NAG), Wilkinson House, Jordan Hill Road, Oxford OX 2 8DR, UK.
The mean follow-up time was 8.3 months, with the longest follow-up being 133 months. Thirty seven patients did not attend for their out-patient follow-up appointments after discharge from the ward. The causes of the injuries are listed in Table I. $44.4 \%$ of the injuries were attributable to sporting injuries, especially racquet sports (57\% of sporting injuries). The frequency of rebleeding appears to be evenly distributed amongst the various causes.

The distribution of the grades of hyphaema on presentation and frequency of rebleeding is presented in Table II. $73 \%$ of patients had a hyphaema occupying less than a third of the anterior chamber on presentation; only $3.5 \%$ had a total hyphaema.

Table III lists the various associated injuries and complications. Secondary haemorrhage occurred in $8.7 \%$ of patients. The time intervals between presentation and rebleeding are shown on Table IV. Of those who had rebleeding, $92.5 \%$ did so in the five days following initial presentation. Data on the interval between the time of injury and presentation were however incomplete. Where this information was available, most patients were noted to present within 24 hours of injury. One patient presented with a secondary haemorrhage following discharge from another hospital, and the time interval to rebleeding for this patient was taken from the time of injury.

\section{TREATMENT RESULTS}

Table $\mathrm{V}$ presents the numbers of patients grouped according to whether or not cycloplegics, steroids, or a combination of both were used. After having first adjusted for age, sex, grade of initial hyphaea and the presence of retinal damage (all $\mathrm{p}>0.05$ ), a statistically significant decrease in the rate of secondary haemorrhage was observed for patients treated with topical steroids $(p=0.005)$. From Table V, it is apparent that the magnitude of this important therapeutic effect of steroid medication was such that patients who received topical steroids had approximately half the rate of secondary haemorrhage compared to those who received no steroid. After adjustment for the above confounding variables, cycloplegic therapy did not affect the rebleeding rate $(\mathrm{p}=0.33)$, and no additional synergistic effect was demonstrated when cycloplegics were combined with topical steroid $(\mathrm{p}=0.81)$.

Two patients required surgical evacuation of blood clots which failed to absorb following secondary haemorrhage. None of the patients with primary traumatic hyphaema alone required surgical blood clot evacuation.

Table II. Size of hyphaema and frequency of rebleeding

\begin{tabular}{lccccc}
\hline $\begin{array}{l}\text { Grade of } \\
\text { hyphaema }\end{array}$ & Number & Rebleed & No Rebleed & \% Rebleed \\
\hline Microscopic & 66 & & 7 & 59 & 11.9 \\
1 & 271 & & 23 & 248 & 9.3 \\
2 & 93 & & 7 & 86 & 8.1 \\
3 & 16 & & 14 & 14.3 \\
4 & 16 & & 1 & 15 & 6.7 \\
\cline { 2 - 2 } Total & 462 & & 40 & & 422 \\
\hline
\end{tabular}


Table III. Complications associated with traumatic hyphaema

\begin{tabular}{lr}
\hline Complications & No. \\
\hline Traumatic mydriasis & 113 \\
IOP $>21$ & 70 \\
Secondary haemorrhage & 40 \\
Cataract & 9 \\
Subluxated lens & 8 \\
Vitreous haemorrhage & 28 \\
Commotio retinae & 57 \\
Retinal tears/detachment & 14 \\
Choroidal rupture & 10 \\
Consequent chronic glaucoma & 2 \\
\hline
\end{tabular}

\section{DISCUSSION}

The age and sex distributions of these data were in broad agreement with those reported in other studies $^{1-3.9-13,15-20,22-24.27-20}$ : males predominated, and 52\% of the patients were under 20 years of age.

This survey did not include patients with traumatic hyphaema who were managed as out-patients. As none of these patients needed admission for secondary haemorrhage, it can be assumed that the vast majority of these cases did not suffer this complication. It can be further inferred that there may have been a slight over-estimation of the rate of secondary haemorrhage from traumatic hyphaema in this study. The observed rate of $8.7 \%$ is, however, in keeping with other Northern European figures for secondary haemorrhage of between $2.4 \%$ and $18 \% .^{1-3,5,9-11}$

Authors from the United States have tended to report a higher rate of secondary haemorrhage, but there is a wide range quoted in these surveys: $3.5 \%$ to $38 \% .^{12-21}$ The average for American studies has been estimated to be between 20 and $25 \% .^{21}$ Differences in the racial make-up of the study populations may explain these discrepancies in that black patients have been found to rebleed more frequently than whites in some mixed population studies. ${ }^{15.31}$ Other studies, however, have not confirmed this finding. ${ }^{12,17,19}$ Reports from predominantly white populations in general do seem to exhibit similarity in their rebleed rates compared with Northern European studies. ${ }^{12.20}$ The use of aspirin is known to predispose to secondary haemorrhage $^{32}$ and its widespread use an an 'over the counter' analgesic in the United States may play a role in increasing the frequency of rebleeding in that country. Although the drug history of this study population prior to admission was unavailable, aspirin was not routinely used as an analgesic for in-patients in this hospital.

Data concerning the complications in those cases of traumatic hyphaema managed on an out-patient basis
Table IV. Interval between injury and rebleeding

\begin{tabular}{cc}
\hline $\begin{array}{c}\text { Interval to rebleed } \\
\text { (days) }\end{array}$ & Number \\
\hline 1 & 6 \\
2 & 17 \\
3 & 8 \\
4 & 4 \\
5 & 2 \\
6 & 1 \\
7 & 1 \\
8 & 1 \\
\hline
\end{tabular}

were not available. Thus the overall frequency of the complications of blunt trauma, such as retinal damage, found in this study may slightly misrepresent the true rates. Data on anterior chamber angle damage were not analysed in this study as gonioscopic findings had not been consistently recorded in the hospital notes.

The grade of hyphaema on presentation and retinal damage were used as indices for the severity of the injury, since these factors are likely to reflect the extent of the initial trauma. By adjustment for these factors in the multivariate analyses an attempt was made to take account of the severity of the injury prior to examining the data for the effects of treatment. The number of patients incurring complications other than retinal damage was too small to allow statistical analysis.

The size of hyphaema on presentation did not influence the probability of secondary haemorrhage. This is in keeping with some studies, ${ }^{8.11 .17}$ but others have noted an increased risk of rebleeding in patients with a larger hyphaema. ${ }^{4,12,13,15,20}$ The occurrence of secondary haemorrhage was not shown to be significantly affected by the presence of retinal damage although there was a weak association $(p=0.074)$. There may, however, have been some overestimation of the frequency of secondary haemorrhage in patients with smaller hyphaemas (including those with retinal damage) as some patients with microscopic hyphaemas may have been managed as outpatients. A definitive conclusion regarding the likelihood of rebleeding in relation to hyphaema size or the presence of retinal damage remains elusive. However, this size indicates that such associations, if they actually do exist, are weak, and would therefore be of doubtful clinical importance as risk indicators for the occurrence of secondary haemorrhage.

The prevention of secondary haemorrhage is an impor-

Table V. Treatment used and frequency of rebleeding

\begin{tabular}{|c|c|c|c|c|c|}
\hline Treatment used & No Rebleed & $(\%)$ & Rebleed & $(\%)$ & Total \\
\hline No cycloplegics or steroids & 168 & $(88.0 \%)$ & 23 & $(12.0 \%)$ & 191 \\
\hline Cycloplegics alone & 50 & $(89.3 \%)$ & 6 & $(10.7 \%)$ & 56 \\
\hline Topical steroids alone & 85 & $(93.4 \%)$ & 6 & $(6.6 \%)$ & 91 \\
\hline $\begin{array}{l}\text { Topical steroids used } \\
\text { (with or without cycloplegics) }\end{array}$ & 204 & $(94.9 \%)$ & 11 & $(5.1 \%)$ & 215 \\
\hline Both steroids and cycloplegics used & 119 & $(96.0 \%)$ & 5 & $(4.0 \%)$ & 124 \\
\hline All patients & 442 & $(91.3 \%)$ & 40 & $(8.7 \%)$ & 462 \\
\hline
\end{tabular}


tant treatment objective. Cycloplegics have been used on the grounds that immobilisation of the iris and ciliary body may prevent secondary haemorrhage by minimising movement of these structures. Cycloplegia also prevents the formation of posterior synechiae and helps to relieve discomfort from concomitant traumatic iritis. ${ }^{25}$ Cycloplegic treatment has been advocated for these reasons. ${ }^{1,9,16}$ Results of controlled trials, however, have not shown it to be of benefit in the prevention of secondary haemorrhage,$^{25}$ and this study supports this finding.

Ocular trauma is often complicated by intra-ocular inflammation. Steroids, either topical or systemic, have been used to counter this response. In this series, topical steroids decreased the frequency of secondary haemorrhage by approximately half. When used systemically, steroids have been found by some investigators to be useful in the prevention of secondary haemorrhage,,$^{22.23,33}$ but the results of a controlled trial did not support their use. ${ }^{24}$ Further to this, systemic steroids can have serious complications. Short courses of systemic steroids have resulted in fatal hyperosmolar hyperglycaemic non-ketotic coma. ${ }^{34}$ Monitored short term use of topical steroid has no known serious side-effects, and our data indicate that such use reduces the incidence of secondary haemorrhage.

The hypothesis that secondary haemorrhage may be related to clot lysis and retraction from traumatised vessels led to the use of systemic antifibrinolytic therapy for traumatic hyphaema. ${ }^{26-30}$ Data on the use of antifibrinolytics have not been analysed in this study because the number of patients managed in this way was too small (10 patients, two of whom had rebleeding). The use of antifibrinolytic agents, however, is not without problems: it may lead to gastro-intestinal symptoms such as nausea, vomiting, diarrhoea and stomach cramps. ${ }^{27}$ Other systemic manifestations, including systemic vascular hypotension, allergic reactions and thromboembolic episodes have been reported. ${ }^{35}$ Significant rises in intraocular pressure related to rapid clot dissolution following the withdrawal of aminocaproic acid have also been reported. ${ }^{36}$

In this study, our data have demonstrated that topical steroid therapy reduced by approximately half the incidence of rebleeding in patients with traumatic hyphaema, whereas topical cycloplegics did not appear to influence the rate of secondary haemorrhage. We conclude that topical steroid should be recommended for the treatment of hyphaema in blunt ocular trauma.

Key words: Topical corticosteroids, Cycloplegics, Hyphaema, Retinal injury, Secondary haemorrhage.

\section{REFERENCES}

1. Ohrstrom A: Treatment of traumatic hyphaema with corticosteroids and mydriatics. Acta Ophthalmol 1972, 50: 549-55.

2. Gregersen E: Traumatic hyphaema. Acta Ophthalmol 1962, 40: 192-9.

3. Sjolie AK and Mortensen KK: Traumatic hyphaema treated ambulatory and without antifibrinolytic drugs. Acta Ophthalmol 1980, 58: 125-8.

4. Agapitos PJ, Noel L-P, Clarke WN: Traumatic hyphaema in children. Ophthalmology 1987, 94: 1238-41.
5. Uusitalo RJ, Ranta-Kemppainen L, Tarkkanen A: Management of traumatic hyphaema in children. An analysis of 340 cases. Arch Ophthalmol 1988, 106: 1207-9.

6. Rasukin W: Traumatic hyphaema. Am J Ophthalmol 1972, 74: 284-92.

7. Shea M: Traumatic hyphaema in children. A review of 113 cases. Canad Med Asn J 1957, 76: 466-9.

8. Lawrence T, Wilson D, Harvey J: The incidence of secondary haemorrhage after traumatic hyphaema. Ann Ophthalmol 1990, Vol 22: 276-8.

9. Oksala A: Treatment of traumatic hyphaema. Acta Ophthalmol 1967, 51: 315-20.

10. Eagling EM: Ocular damage after blunt trauma to the eye. Br J Ophthamol 1974, 58: 126-40.

11. Kearns P: Traumatic hyphaema: a retrospective study of 314 cases. Br J Ophthalmol 1991, 75: 137-41.

12. Kennedy RH and Brubaker RF: Traumatic hyphema in a defined population. Am J Ophthalmol 1988, 106: 123-30.

13. Edwards WC and Layden WE: Traumatic hyphema. A report of 184 consecutive cases. Am J Ophthalmol 1973, 75: 110-16.

14. Edwards WC and Layden WE: Monocular versus binocular patching in traumatic hyphema. Am J Ophthalmol 1973, 76: 359-62.

15. Spoor TC, Kwitko GM, O'Grady JM, Ramocki JM: Traumatic hyphaema in an urban population. Am J Ophthalmol 1990, 109: 23-7.

16. Thygeson $\mathrm{P}$ and Beard C: Observations on traumatic hyphaema. Am J Ophthamol 1952, 35: 977-85.

17. Thomas MA, Parrish RK, Feuer WJ: Rebleeding after traumatic hyphaema. Arch Ophthalmol 1986, 104: 206-10.

18. Loring MJ: Traumatic hyphaema. Am J Ophthalmol 1958, 46: $873-80$.

19. Read J and Goldberg MF: Comparison of medical treatment for traumatic hyphaema. $\operatorname{Tr}$ Am Acad Ophthalmol and Otol 1974, 78: 799-815.

20. Witteman GJ, Brubaker SJ, Jahnson M, Marks RG: The incidence of rebleeding in traumatic hyphaema. Ann Ophthalmol 1985, 17: 525-9.

21. Wilson FM: Traumatic hyphaema. Pathogenesis and management. Ophthalmology 1980, 87: 910-19.

22. Rynne MV and Romano OE: Systemic corticosteroids in the treatment of traumatic hyphema. J Pediatr Ophthalmol Strabismus 1980, 17: 141-3.

23. Yasuna E: Management of traumatic hyphaema. Arch Ophthalmol 1974, 91: 190-1.

24. Spoor TC, Hammer M, Belloso H: Traumatic hyphema. Failure of steroids to alter its course: a double-blind prospective study. Arch Ophthalmol 1980, 98: 116-19.

25. Gilbert HD and Jensen AD: Atropine in the treatment of traumatic hyphema. Ann Ophthalmol 1973, 5: 1297-300.

26. Kraft SP, Christianson MD, Crawford JS, Wagman RD, Antoszyk JH: Traumatic hyphaema in children. Treatment with epsilon-aminocaproic acid. Ophthalmology 1987, 94: 1232-7.

27. McGetrick JJ, Jampol LM, Goldberg MF, Frenkel M, Fiscella RG: Aminocaproic acid decreases secondary haemorrhage after traumatic hyphema. Arch Ophthalmol 1983, 101: 1031-3.

28. Kutner B, Fourman S, Brein K, Hobson S, Mrvos D, Sheppard $\mathrm{J}$, et al.: Aminocaproic acid reduces the risk of secondary hemorrhage in patients with traumatic hyphema. Arch Ophthalmol 1987, 105: 206-8.

29. Uusitalo RJ, Saari MS, Aine E, Saari KM: Tranexamic acid in the prevention of secondary hemorrhage after traumatic hyphema. Acta Ophthalmol 1981, 59: 539-45.

30. Varnek L, Dalsgaard C, Hansen A, Klie F: The effect of tranexamic acid on secondary hemorrhage after traumatic hyphema. Acta Ophthalmol 1980, 58: 787-93.

31. Parmer DJ, Goldberg MF, Frenkel M, Fiscella R, Anderson 
RJ: A comparison of two dose regimens of epsilon aminocaproic acid in the prevention and management of secondary traumatic hyphema. Ophthalmology 1986, 93: 102-8.

32. Ganley JP, Geiger JM, Clement JR, Rigby PG, Levy GJ: Aspirin and recurrent hyphema after blunt ocular trauma. Am J Ophthalmol 1983, 96: 797-801.

33. Romano PE: Pro steroids for systemic antifibrinolytic treatment for traumatic hyphema. J Pediatr Ophthalmol Strabismus 1986, 17: 92-5.

34. Fujikawa LS, Meisler DM, Nozik RA: Hyperosmolar hyper- glycemic nonketotic coma: a complication of short-term systemic corticosteroid use. Ophthalmology 1983, 90: $1239-41$.

35. Romano P: Systemic steroids or aminocaproic acid in the management of traumatic hyphema? Yes! [Letter] Arch Ophthalmol 1984, 102: 189-92.

36. Dieste MC, Hersh PS, Kylstra JA, Larrison WI, Frambach DA, Shingleton BJ: Intraocular pressure increase associated with epsilon-aminocaproic acid therapy for traumatic hyphema. Am J Ophthalmol 1988, 106: 383-90. 